\title{
Comparative Study between Results of Bipolar Hemiarthroplasty And Cannulated Screws in Management of Fracture Neck Femur in Old Age Group
}

\author{
TALAAT T. EL-HADIDI, M.D.*; HISHAM M. SOLIMAN, M.D.*; AHMED H. ABD EL-AZEEM, M.D.*; \\ OMAR A. SHALABY, M.Sc.**; MOHAMED H.E. ABORAS, M.Sc.**; MOHAMED A. ABOKISHK, M.Sc.**; \\ BAHAAALDINE S. ABD EL-WAHAB, M.Sc.*; REDA A.A. SHETA, M.Sc.* and MOEMEN SEIF, M.Sc.*
}

The Department of Orthopedic Surgery, Faculty of Medicine, Cairo University* and Damnhour Medical National Inistitute**

\begin{abstract}
Background: While the treatment for displaced femoral neck (Garden types I and II) is still the subject of controversy.

Aim of Study: The aim of this thesis is to compare the results of internal fixation and bipolar hemiarthroplasty in non-displaced fracture neck of femur in elderly patients.

Patients and Methods: The study was performed on 3 patients over 60 years with non-displaced fracture neck of femur, 15 of them treated with internal fixation by cannulated screws, while the other 15 treated by bipolar arthroplasty.

Results: All patients were followed up for a mean period of 12 months radiologically by serial X-rays and clinicaly by Harris hip score, where the overall mean Harris Hip score in fixation group was 74, while it was 86.3 for the replacement group.

Conclusion: There was a significant relationship between the time of delay of operation and the final outcome in fixation group. There was no significant relationship between the final outcome and age, sex, and garden type of the fracture.
\end{abstract}

Key Words: Non-displaced fracture neck of femur-Elderlyinternal fixation - Bipolar arthroplasty.

\section{Introduction}

DESPITE marked improvements in implant design, surgical technique, and patient care, hip fractures continue to consume a substantial proportion of our health care resources [1]. Femoral neck fractures usually are entirely intracapsular, with synovial fluid bathing the fracture may interfere with the healing process. These factors, along with the precarious blood supply to the femoral head, make healing unpredictable and nonunion fairly frequent [2]. Internal fixation with cannulated screws is a

Correspondence to: Dr. Talaat T. El-Hadidi, The Department of Orthopedic Surgery, Faculty of Medicine, Cairo University simple, safe, economical, and reasonably effective procedure for the treatment of non-displaced femoral neck fractures in elderly population [3]. Hemiarthroplasty avoid the problems of fixation failure, nonunion, and avascular necrosis that are associated with reduction and fixation, it exposes the patient to the risks of arthroplasty [4] . The aim of introducing bipolar hemiarthroplasty in the 1970s was to prevent the development of endoprosthetic arthritis. Some motion is carried among the components of the prosthesis, which theoretically diminishes acetabular wear [5].

\section{Patients and Methods}

From June 2014 to October 2016, a single comparative prospective randomized study was undertaken to assess the results of fixation of nondisplaced fracture neck femur in elderly (above sixty) by canuulated screws versus replacement by bipolar arthroplasty. Thirty patients were operated upon divided into 2 groups. Fifteen patients had cannulated screw fixation, while the other 15 patients had bipolar arthroplasty. The patients were followed up for a mean of 12 months. All patients were operated at Damnhour Medical National Institute and Cairo university hospitals, inclusion criteria: Elderly population (above sixty) suffering from non-displaced femoral neck fracture (Garden I, II), exclusion criteria: Patients under sixty, previous hip surgeries, hip deformities, fracture extension to the proximal femur, associated shaft fracture, pathological fractures, displaced fracture (Garden III, IV).

Surgical data and post-operative care: In all patients spinal and epidural anesthesia was used, fixation patients positioned on a radiolucent table 
with the involved extremity on a fracture table. Fixation by three 7.3 cannulated screws positioning in an inverted triangular pattern with two screws superior anterior and superior-posterior, and 1 screw inferior-central. Replacement patients positioned in the lateral decubitus position, using lateral hip approach the fracture is opened, proper entery pointand anteversion were attempted, correct diameter of the head is then verified, reamers then used to create space for the stem. Insertion of stem and head trials and dislocation if accepted to prepare the medulla for cementation by second generation technique, the bipolar head gently taped and reduction attempted with capsular closure. We advised arthroplasty patients to bear weight immediate post-operative and to do strengthening exercises without active abduction against resistance, no adduction past neutral, no external rotation and no extension. They were learnt how to get outside the bed, how to climb stairs, how to get inside and outside the car, and when to drive cars. On the other side fixation patients were trained on the proper gait 6 weeks post-operative, advised to have strengthening exercises without precautions.
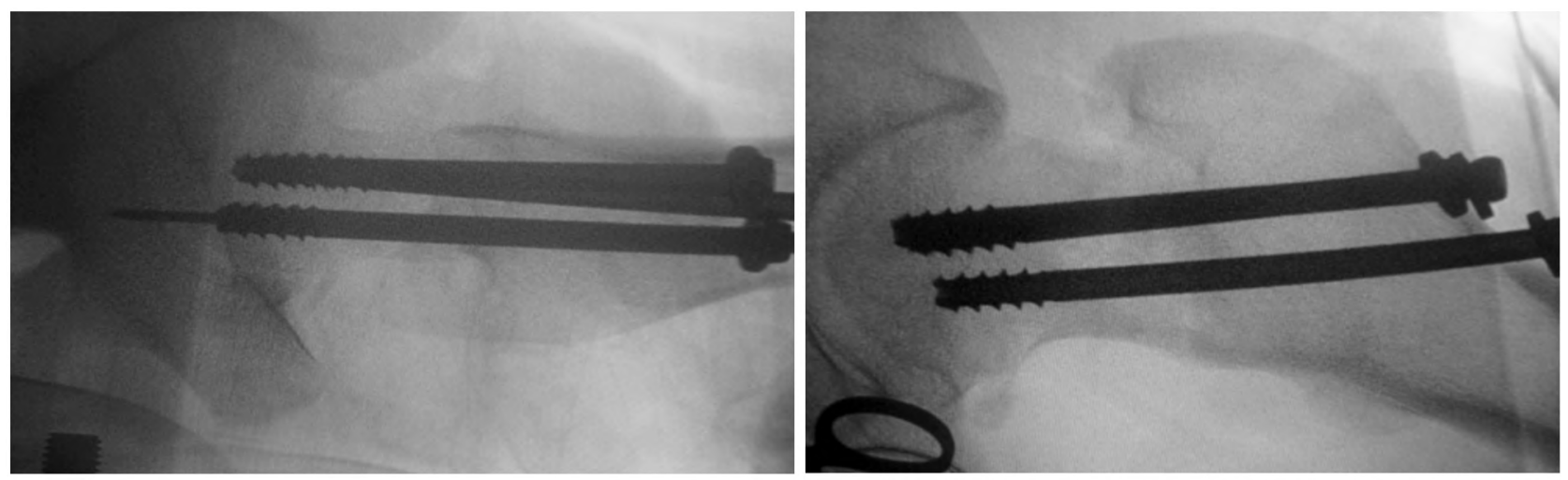

Fig. (1): Final positioning of the screws in AP, LAT views.

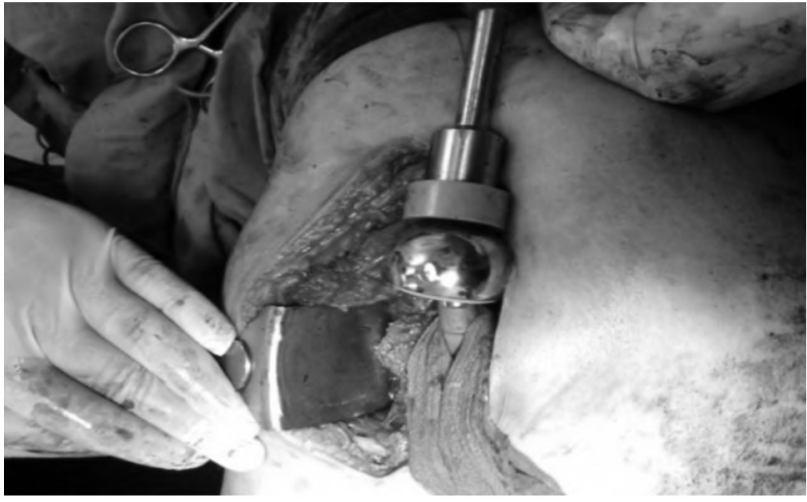

Fig. (2): Prosthesis reduction.

\section{Results}

The overall mean Harris Hip Score in fixation group was 74 , while it was 86.3 for the replacement group with no statistically significant difference between the functional outcomes of both groups. There was a significant relationship between the time of delay of operation and the final outcome in fixation group. There was no significant relationship between the final outcome and age, sex, and garden type of the fracture.

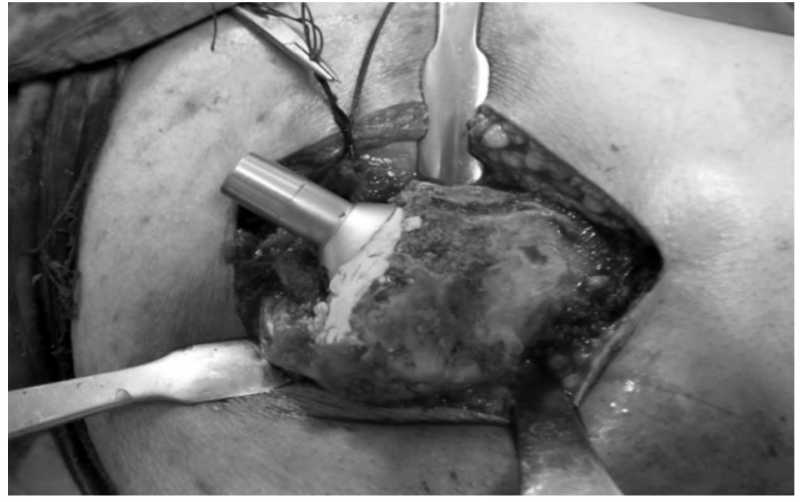

Fig. (3): Final stem inserted.

Complications: In fixation group, we have $13.3 \%$ incidence of nonunion (2 patients), $13.3 \%$ incidence of avascular necrosis (2 patients), and $6.7 \%$ incidence of screw cutout (1 patient). The reoperation rate in this group was $20 \%$. In arthroplasty group, we have $13.3 \%$ incidence of aseptic loosening (2 patients), $6.7 \%$ incidence of deep infection (1 patient), $6.7 \%$ incidence of heterotropic ossification (1 patient), and $6.7 \%$ incidence of dislocation (1 patient). The reoperation rate in this group was $13.3 \%$. 


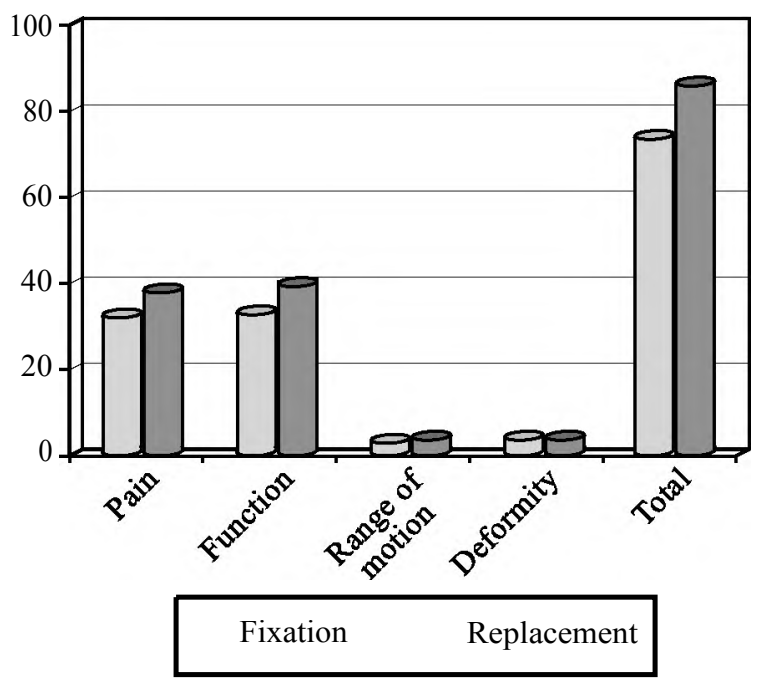

Fig. (4): Bar chart showing the mean Harris hip scores in both groups.

\section{Discussion}

In the present study, 30 patients with nondisplaced fracture neck of femur were divided into two groups from June 2014 to October 2016. First group patients were treated by internal fixation using cannulated screws. The other group patients were treated by bipolar arthroplasty. In the present study the mean follow-up was 12 months compared to 6 months-2 years in Wei-Chih Chen et al., Eisler et al., studies, in Oguz Karaeminogullari et al., [6-8]. The mean age in the fixation group was 70 compared to 83.7 in Wei-Chih Chen et al., study, 68 years in Kemler et al., study [6,9]. While the mean age in the replacement group was $72 \mathrm{com}-$ pared to 77.2 in Joon Soon Kang et al., study, 76 years in Jeff Chien-Fu Lin study [10,11]. We found no significant relation between the age and final results. The mean time of delay of fixation was 69 hours in our study compared to 21 hours in Kemler et al., study [9] and to 63 hours in Joon Soon Kang et al., study [10]. We found that delaying of treatment had statistically significant relation with the end results of fixation patients which is comparable to many other studies that found significant relation between the mean time of delay of fixation and the final outcome like Oguz Karaeminogullari et al and Nikolopoulos KE et al., [8,12]. The reoperation rate in fixation patients in our study was $20 \%$ compared to $13-19 \%$ in Joon Soon Kang et al., Manohara et al., studies [10,13] . On the other side, the reoperation rate of hemiarthroplasty patients in our study was $13.3 \%$, while it was $1 \%-7 \%$ Joon Soon Kang et al., Philipp von Roth et al., studies [10,14] . Our mean Harris Hip Score was 74 in the fixation patients compared to 62 and 82 in Kasettiet al, Xiaobin et al., studies $[\mathbf{1 5}, \mathbf{1 6}]$. While our mean Harris Hip Score was 86.3 in hemiarthroplasty patients compared to 77 and 86.9 in Paul T.P.W. Burger, K. Karthik Narayan studies $[\mathbf{1 7 , 1 8}$. No mortalities recorded in our study. Davison et al., Bhandari et al., $[\mathbf{1 9 , 2 0}]$ reported a higher mortality rates in arthroplasty than in fixation patients of no displaced fracture neck of femur. Nonunion rate was $13.3 \%$ in our study, while in Manohara et al., Wei-Chih Chen et al., studies, $[\mathbf{1 3 , 6 ]}$ the nonunion rates was $5-25 \%$. Avascular necrosis rate was $13.3 \%$ in our study, while in Oguz Karaeminogullari et al., Manohara et al., studies, $[\mathbf{8 , 1 3}]$ the avascular necrosis rates was 5-9\%. Dislocation rate in our study was $6.7 \%$, while in Bashar et al., Martyn et al., studies, [21,22] the dislocation rate was $2.5 \%$ to $5 \%$. Regarding deep infection in our study, in hemiarthroplasty patients, it was $6.7 \%$ with no recorded cases of infection in fixation patients. Wang et al., Bhandari et al., studies $[\mathbf{2 3 , 2 0}]$ reported a higher rate of infection in arthroplasty than in fixation.

We concluded at the end of this study and after reviewing the literature, that primary bipolar hemiarthroplasty for elderly patients with non-displaced fracture neck of femur is preferred for internal fixation in patients who have any of the followings; age above seventy, poor bone quality (osteoporosis), posterior fracture comminution, delayed fracture fixation (after 48 hours). Otherwise, internal fixation is considered as simple, safe, economically, and reasonably effective procedure for the treatment of non-displaced femoral neck fractures in elderly patients. To decrease the reoperation rate in internal fixation, we recommend using CT scan to detect posterior comminution and using DEXA scan to detect osteoporosis.

\section{References}

1- ROCKWOOD C.A., GREEN D.P., BUCHOLZ R.W. and HECKMAN J.D.: Fractures of the neck of the femur. Rockwood \& Green Fractures in Adults, 6 (2): 1754, 2006.

2- CANAL and BEATY: Fractures and Dislocations of the Hip. Campell Operative Orthopedics, 11 (4): 3271, 2007.

3- CHEN W.C., YU S.W., TSENG I.C., SU J.Y., TU Y.K. and CHEN W.J.: Treatment of non-displaced femoral neck fractures in the elderly. J. Trauma., 58 (5): 1035-9, 2005.

4- ROCKWOOD C.A., GREEN D.P., BUCHOLZ R.W. and HECKMAN J.D.: Fractures of the neck of the femur, Rockwood \& Green Fractures in Adults., 7 (4): 1578, 2010.

5- RAIA F.J., CHAPMAN C.B., HERRERA SCHWEPPE M.W., MICHELSEN C.B and ROSENWASSER M.P.: Unipolar or bipolar hemiarthroplasty for femoral neck fractures in the elderly? Clinical Orthopaedics and Related Research., 414 (9): 259-65, 2003. 
6- WEI-CHIH CHEN, M.D., SHANG-WON YU, M.D., ICHUAN TSENG, M.D., JUIN-YIH S.U., M.D., YUANKUN T.U., M.D., Ph.D. and WEN-JER CHEN, M.D., Ph.D.: Treatment of Non-displaced Femoral Neck Fractures in the Elderly. J. Trauma., 58: 1035-9, 2005.

7- EISLER J., CORNWALL R., STRAUSS E., KOVAL K., SIU A. and GILBERT M.L.: Outcomes of elderly patients with non-displaced femoral neck fractures. Clin. Orthop. Relat. Res., 399: 52-8, 2002.

8- OGUZ KARAEMINOGULLARI, HUSEYIN DEMIRORS, MESUT ATABEK, CENGIZ TUNCAY, REHA TANDOGAN and METIN OZALAY: Avascular necrosis and nonunion after osteosynthesis of femoral neck fractures: Effect of fracture displacement and time to surgery. Advances in Therapy, 21 (5): 335-42, 2004.

9- M.A. KEMLER, M. De VRIES W.J.E. GERARD, J.J.A.M VAN RAAY and A. VAN DER TOL: Can we predict failure of internal fixation when treating femoral neck fractures? Eur. J. Orthop. Surg. Traumatol., 17: 67-70, 2007.

10- JOON SOON KANG, YOON SANG JEON, CHI HOON AHN and TAE HOON ROH.: Osteosynthesis versus endoprosthesis for the treatment of femoral neck fracture in Asian elderly patients. BMC Musculoskeletal Disorders, 17: 264, 2016.

11- JEFF CHIEN-FU LINAND WEN and MIIN LIANG: Outcomes after fixation for non-displaced femoral neck fracture compared to hemiarthroplasty for displaced femoral neck fracture among the elderly. B.M.C. Musculoskeletal. Disorders, 16: 199, 2015.

12- NIKOLOPOULOS K.E.: Long term outcome of patients with avascular necrosis after internal fixation of femoral neck fractures. Injur., 34: 525-8, 2003.

13- MANOHARA R., LIANG S., HUANG D. and KRISHNA L.: Cancellous screw fixation for non-displaced femoral neck fractures in the elderly. J. Orthop. Surg. (Hong Kong)., 22 (3): 282-6, 2014

14- PHILIPP VON ROTH, MATTHEW P. ABDEL, W. SCOTT HARMSEN and DANIEL J. BERRY.: Cemented Bipolar Hemiarthroplasty Provides Definitive Treatment for Femoral Neck Fractures at 20 Years and Beyond. Clinical Orthopaedics and Related Research, 473 (11): 3595-9, 2015.

15- KASETTI J., RAVIKUMAR and GAVIN MARSH: In- ternal fixation versus hemiarthroplasty versus total hip arthroplasty for displaced subcapital fractures of femur: 13 year results of a prospective randomised study. Injury, 31 (10): 793-7, 2000.

16- XIAOBIN CHEN, JIANZHENG ZHANG, XINLING WANG, JIXIN REN and ZHI LIU: Incidence of and Factors Influencing Femoral Neck Shortening in Elderly Patients after Fracture Fixation with Multiple Cancellous Screws. Med. Sci. Monit., 23: 1456-63, 2017.

17- PAUL T.P.W. BURGER, ARNOUD R.VAN GEENE, MICHEL P.J. VANDEN BEKEROM, ESTHER M.M VAN LIESHOUT,BASTIAAN BLOM, ILYAS S. ALEEM, M. BHANDARI and RUDOLF WPOOLMAN: Total hip arthroplasty versus hemiarthroplasty for displaced femoral neck fractures in the healthy elderly: A metaanalysis and systematic review of randomized trials. International Orthopaedics, 36 (8): 1549-60, 2012.

18- K. KARTHIK NARAYAN and THOMAS GEORGE: Functional outcome of fracture neck of femur treated with total hip replacement versus bipolar arthroplasty in a South Asian population. Archives of Orthopaedic and Trauma Surgery, 126 (8): 545-8, 2006.

19- DAVIDSON J., CALDER S., ANDERSON G., JAGGER C., HARPER W. and GREGG P.: Treatment for displaced intracapsular fracture of the proximal femur. J.B.J.S., 83 (B): 206-12, 2001.

20- BHANDARI M., DEVEREAUX J. and SWIONTKOWSKI F.: Internal fixation compared with arthroplasty for displaced fractures of the femoral neck: A metaanalysis. J.B.J.S., 85 (A): 1673-81, 2003.

21- BASHAR A., SOHAIL B., JANHAVI S., PAUL K., AMIRAM G. and MOHIT B.: Treatment of displaced femoral neck fractures in the Elderly. A cost-benefit analysis. J. Orthop. Trauma., 23 (6): 442-6, 2009.

22- MARTYN J. PARKER, F.R.C.S. (EDIN), M.D., ROSHAN RAGHAVAN, M.B., B.S. and KURINCHI GURUSAMY, M.B., B.S., F.R.C.S.: Incidence of fracture-healing complications after femoral neck fractures. Clinical Orthopaedics and Related Research, 485: 175-9, 2007.

23- WANG J., JIANG B., MARSHALL R. and ZHANG P.: Arthroplasty or internal fixation for displaced femoral neck fractures: Which is the optimal alternative for elderly patients? A meta-analysis. International Orthopaedics (SICOT), 33: 1179-87, 2009. 


\section{دراسة مقارنة بين نتائج نصف المفصل ثنائى القطب

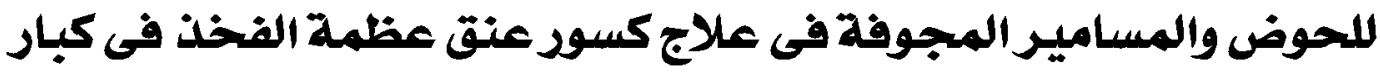

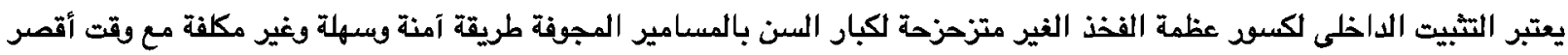

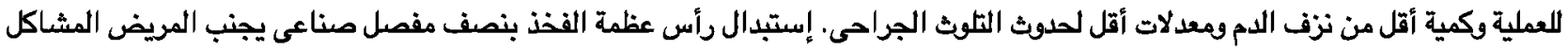

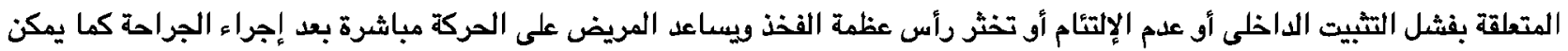

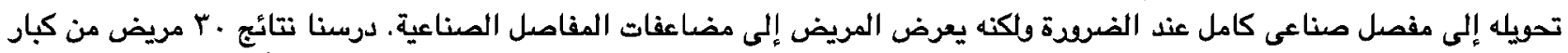

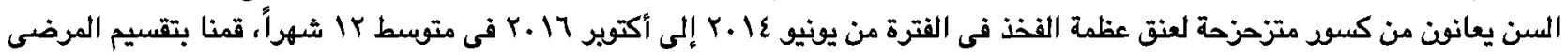

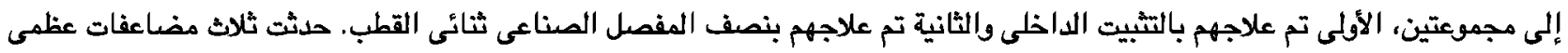

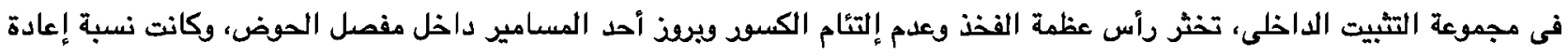

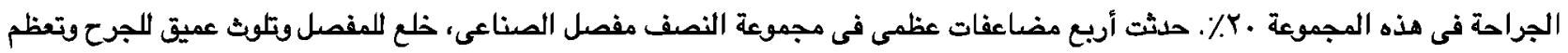

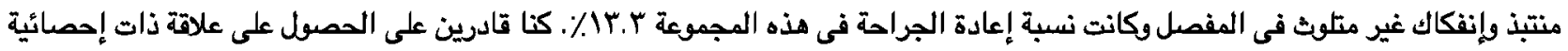

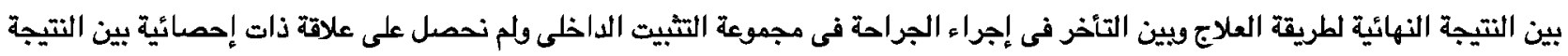

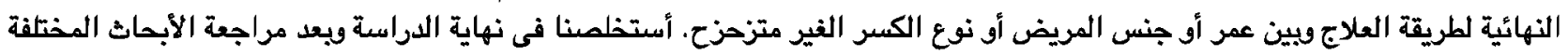

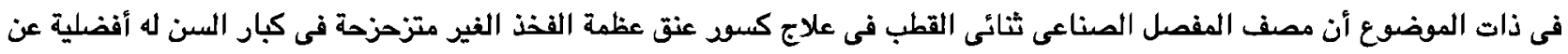

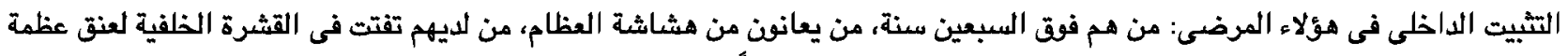

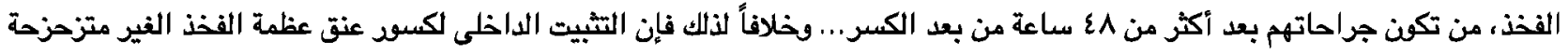

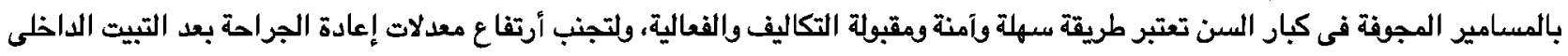

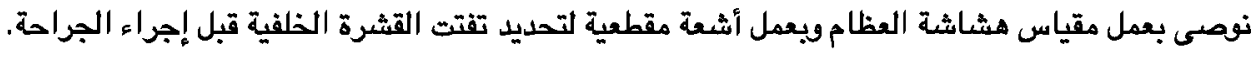

